原著

\title{
頸動脈内膜剝離術の合併症と長期予後
}

\author{
黒田敏, 上山 博 康, 宝 金 清 博 $^{1}$ \\ 阿部弘, 野 村 三起夫, 斎藤 久 壽 $^{2}$ \\ 小岩 光 行, $^{3}$ 柏葉 武, 三森 研 自 $^{4}$
}

\section{Ischemic Complications and Late Prognosis of Carotid Endarterectomy}

Satoshi Kuroda, M.D., ${ }^{1}$ Hiroyasu Kamiyama, M.D., ${ }^{1}$ Kiyohiro Houkin, M.D., ${ }^{1}$

Hiroshi Abe, M.D., Mikio Nomura, M.D., ${ }^{2}$ Hisatoshi SAitoh, M.D., ${ }^{2}$

Mitsuyuki Korwa, M.D., ${ }^{3}$ Takeshi Kashiwaba, M.D., ${ }^{3}$ and Kenji Mitsumori, M.D.

${ }^{1}$ Department of Neurosurgery, Hokkaido University School of Medicine, ${ }^{2}$ Sapporo

Azabu Neurosurgical Hospital, ${ }^{3}$ Kashiwaba Neurosurgical Hospital, and

${ }^{4}$ Hokkaido Neurosurgical Memorial Hospital, Sapporo, Japan

Summary : In this report, we reviewed surgical results, complications and late prognosis of 73 carotid endarterectomies on 63 patients with cervical carotid artery stenosis in the last 6 years. We performed microsurgical endartrectomy with internal shunts and electrophysiological monitoring, such as EEG and somatosensory evoked potentials. Perioperative complications were found in 7 patients $(9.6 \%)$, cerebral infarction in 4 patients, transient hypoglossal nerve palsy in one, acute hepatitis in one, and pneumonia in one. In 2 patients, thromboembolism, caused by a transient obstruction of internal shunts, resulted in major neurological deterioration. On the other hand, hemodynamic ischemia caused no or minor neurological deterioration in 2 patients who had severe stenosis of the carotid artery and reduced perfusion reserve. In follow-up periods (mean 24.5 months), 4 patients $(5.5 \%)$ have developed cerebral infarction, ipsilateral carotid artery territory in three $(4.1 \%)$ and vertebrobasilar artery territory in one. Another patient died of myocardial infarction. We mainly discussed how to avoid perioperative complications, especially cerebral infarction, in this report.

\section{Key words :}

- carotid endarterectomy

- complication

- prognosis

- surgical results

\section{はじめに}

頸部内頸動脈の狭窄病変に対する内膜剥離術 (carotid endarterectomy，以下 CEA）は，高度の狭窄による脳血流 不全を改善したり, 塞栓源を除去することで, 一部の症例 では, 内科的治療より優る脳梗塞の予防効果を有するとさ れている ${ }^{12)}$. 今後, 手術適応の決定をより洗練させるこ とにより，より多くの効果を期待できると考えられる.
しかし, 本術式に伴う合併症も決して少なくなく, なか でも脳虚血による合併症は予後に大きく影響するといわれ ている(2)5)6)9) 10)13)18) 21) 23).

今回，われわれは，CEAを施行した症例について，手 術適応，長期予後をあらためて検討するとともに， CEA 術中に生じた脳虚血合併症の経験から，その原因と対策を 検討したので報告する.

${ }^{1}$ 北海道大学 脳神経外科, ${ }^{2}$ 札幌麻生脳神経外科病院, ${ }^{3}$ 柏葉脳神経外科病院, ${ }^{4}$ 北海道脳神経外科記念病院（受稿日 1992.10.6) 〔連絡先： ₹060 札幌市北区北 15 条西 7 丁目 北海道大学医学部 脳神経外科 黒田 敏〕〔Mailing address: Satoshi Kuroda, M.D., Department of Neurosurgery, Hokkaido University School of Medicine, North 15 West 7, Kita-ku, Spporo 060, Japan] 


\section{対 象，方 法}

過去 6 年間 $(1985$ 年 10 月〜 1991 年 9 月) に北海道大学脳 神経外科および札幌市内の関連施設にて, 内頸動脈狭窄症 に対して行われた 63 例 73 側の CEA を対象とした. 男性 56 例, 女性 7 例, 平均年齢は 55.0 歳 (37〜78 歳)であった. 術後の経過観察期間は, 平均 24.5 力月 ( 1 - 64 力月) であ る.

われわれは, CEA を施行するにあたり，(1)症候性の場 合, TIA から minor completed stroke を呈し, 75\%以上 の内頸動脈狭窄，または，塞栓源となりうる潰瘍形成を有 する症例，および，(2)無症候性の場合，80〜90\%以上の 内頸動脈狭窄を有する症例を手術適応とした.

発症形式は, 内頸動脈領域の TIA 21 例, RIND 6 例, minor completed stroke 30 例であった.このほか, 椎骨 脳底動脈領域の TIA, MiCSにて発症し, 脳血管撮影で 内頸動脈に高度の狭窄 (90\%以上) 認めた 6 例に対しても CEAが施行された。

脳血管撮影では, 内頸動脈狭窄の程度は $90 \%$ 以上の例 が 19 側, 75〜90\%の例が 14 側，50〜 75\%の例が 14 側, $50 \%$ 以下の例が 4 側であった。狭窄度にかかわらず，明ら かな潰瘍形成を 22 側に認めた. 内頸動脈の狭窄が $75 \%$ 以 下の症例では，全例に潰瘍形成を疑わせる所見を認めた.

手術は, 脳虚血発作から 4 週間以上経過したのちに, 同 一の術者 (上山)により施行された. 全身麻酔下に内シャン トチューブを全例に用いて行った。 また, 術中, 脳波ある いは体性感覚誘発電位 (SEP)によるモニタリングを全例で 使用した。術中の heparinizationは行わなかった.

また，術後，経過観察期間中は全例でチクロピジン 200 $\mathrm{mg} /$ day の経口投与を行った.

\section{結果}

\section{1. 手 術適応}

前述の手術適応にしたがって手術を施行した。適応の決 定にあたっては, 従来どおり, 脳血管撮影による所見を最 も重視してきたが, 必ずしも, 脳血管撮影だけでは, 塞栓 源となる潰瘍を検出できない症例も 5 例, 経験された. 代 表的例を提示する.

$<$ 症 例 $>$

65 歳, 男性. 1 力月のうちに 2 回の右片麻痺, 失語症 の発作を繰り返し, 精査のため, 入院となった. 脳血管撮 影では, 左内頸動脈起始部に中等度の狭窄を認めたが, 明 らかな潰瘍形成はみられなかった(Fig. 1). したがって, チクロピジン $200 \mathrm{mg} / \mathrm{day} に て$ 保存的に経過を観察してい たところ，3 カ月後に同様の脳虚血発作が出現した.

脳血管撮影では, 明らかな変化はみられなかったが, 塞

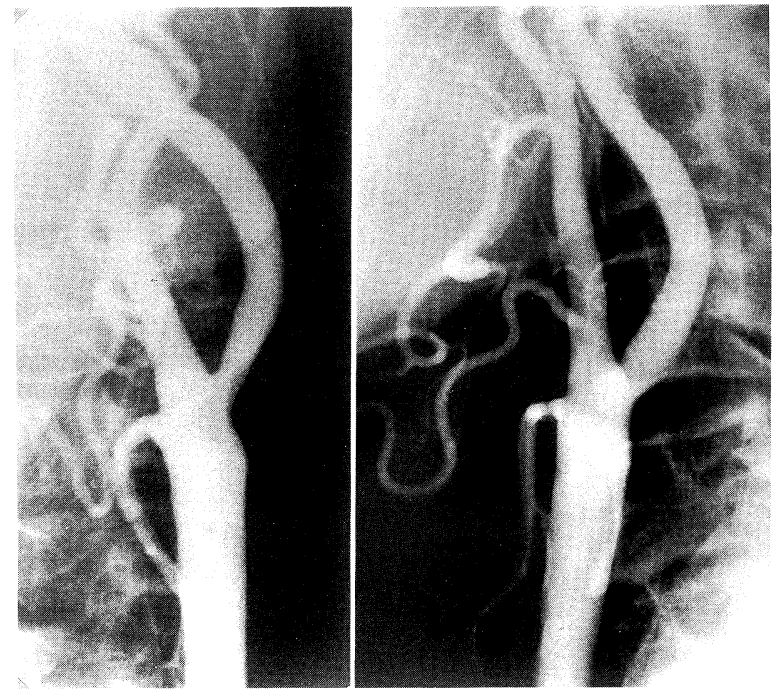

Fig. 1 Left carotid angiograms of 65-years-old male (Case 1) who developed minor completed stroke, including right hemiparesis and motor dominant aphasia. He experienced recurret ischemic episode 3 months after medical treatment was started. Angiograms revealed smooth-surface plaque and moderate stenosis of the left internal carotid artery origin. No definite findings of ulcer formation was shown.

栓源の検索, 除去を目的に CEA を施行した. 頸動脈を切 開すると, 内頸動脈起始部には大きな潰瘍が形成されてお り, 塞栓源となっている可能性がつよく示唆された (Fig. 2).

術後 10 カ月が経過するが, 新たな絧虚血発作は出現し ていない.

\section{2. 術中合併症}

術中, 術後の合併症は 7 例 $(9.6 \%)$ で，その内訳は脳梗 塞 4 例, 一過性舌下神経麻㾝 1 例, 劇症肝炎 1 例, 肺炎 1 例である.

このうち，脳梗塞による合併症を生じた 4 例 (5.5\%)を 中心に検討した (Table 1).

4 例のうち 2 例は, 内シャントチューブに起因したと思 われる脳塞栓が, 内頸動脈あるいは中大脳動脈領域に広範 な脳梗塞を形成し, 重篤な神経症状をきたした. 内頸動脈 領域に広範な脳梗塞をきたした例は脳へルニアにより死亡 した. いずれの症例においても, 手術操作中, シャントチ ューブの近位端が血管壁にあたって閉塞したことに気づく のが遅れ, チューブ内に形成された血栓が再び血流が回復 した時に頭蓋内へ流入したためと考えられた。 これらの 2 例では，いずれも two-way shunt tube を使用していた. そのほかの 2 例では, 内頸動脈の狭窄が極めて高度で,

10 脳卒中の外科 $22: 1994$ 


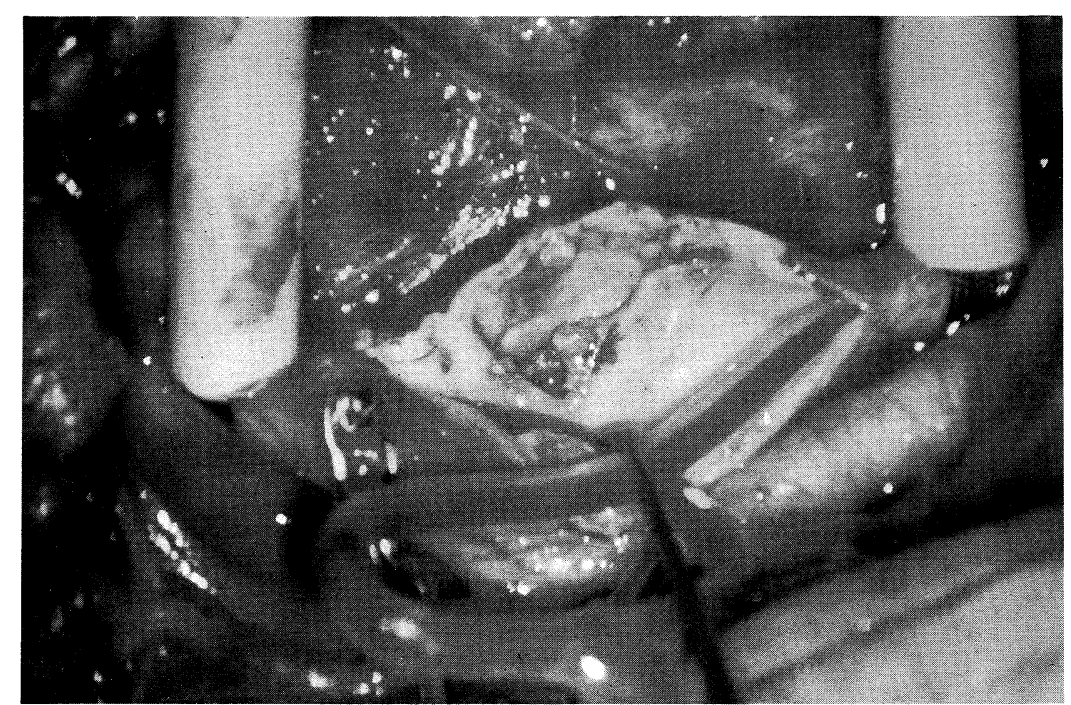

Fig. 2 Intraoperative photograph of Case 1, demonstrating large ulcer at the origin of the left internal carotid artery. He have experienced no ischemic episode in 10 months after operation.

Table 1 Summary of 4 cases who developed perioperative ischemic stroke

\begin{tabular}{|c|c|c|c|c|c|c|}
\hline & Age/Sex & Diagnosis & Postop. CT scans & Postop. symptom & Prognosis & Cause \\
\hline Case 1 & $65 \mathrm{~F}$ & $\begin{array}{l}\text { Rt. ICA stenosis } \\
(90 \%)\end{array}$ & infarction (rt. MCA territory) & $\begin{array}{l}\text { Lt. hemiparesis } \\
\text { (improved in a month) }\end{array}$ & fair & embolic \\
\hline Case 2 & $50 \mathrm{M}$ & $\begin{array}{l}\text { Rt. ICA stenosis } \\
(80 \%)\end{array}$ & infarction (rt. ICA territory) & $\begin{array}{l}\text { cons. disturbance, } \\
\text { Lt. hemiplegia }\end{array}$ & dead & embolic \\
\hline Case 3 & $66 \mathrm{M}$ & $\begin{array}{l}\text { Rt. ICA stenosis } \\
(99 \%)\end{array}$ & small infarction (rt. parietal lobe) & none & excellent & hemodynamic \\
\hline Case 4 & $60 \mathrm{M}$ & $\begin{array}{l}\text { Rt. ICA stenosis } \\
(90 \%)\end{array}$ & infarction (rt. watershed zone) & deterioration of lt. hemiparesis & good & hemodynamic \\
\hline
\end{tabular}

術前の検討にて，脳血流量および acetazolamide 反応性の 著しい低下を認め, critical hypoperfusion が存在すると考 えられた。いずれもシャントチューブを挿入するためのわ ずかな血流の遮断時間 ( 5 分間前後)による hemodynamic mechanism が合併症の原因と考えられた。1例では術後 の新たな神経症状は出現しなかったが，1例では術前から 存在した片麻痺の増悪，梗塞巣の拡大を認めた。

以下，代表的症例を提示する.

\section{$<$ 症例 $1>$}

65 歳，女性. 左上下肢の脱力にて発症した。脳血管撮 影では，右内頸動脈に約 $90 \%$ の狭窄を認めた。 2-way shunt tube を挿入後, 内膜剝離術を施行していたが, 途中 シャントチューブ内の血流が不良なのに気が付き，チュー ブの位置を若干，変えたところ， SEP の $\mathrm{N}_{20}$ amplitude が 一過性に低下し，チューブ内の血流は良好となった。しか し, 術後, 右中大脳動脈領域の脳梗塞が生じ, 左片麻痺が 出現した。

$<$ 症例 $3>$

66 歳，男性. 左上下肢の脱力にて発症した，MRIにて
右大脳半球深部白質に多発する小梗塞を認めるのみであっ た. 脳血管撮影では，高度の右内頸動脈狭窄を認めた

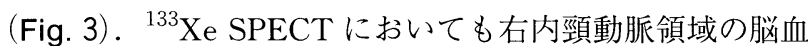
流量, acetazolamide 反応性の著しい低下を認め，脳血流 不全が存在すると考えられた。

術中，内シャントチューブを挿入するため，内頸動脈の 血流を遮断すると，血流再開までの約 5 分間の間に SEP の $\mathrm{N}_{20}$ amplitude の低下を認めた (Fig. 4). 内シャントチ ューブの血流を再開させたところ，内頸動脈からの逆流か 認められず，遠位部の急速な血栓化が疑われた。吸引およ び heparin 加生理食塩水による flash を繰り返すうちに内 頸動脈の patency が回復した. 以後, 通常のとおり手術を 継続し，終了した，術後，新な神経症状は出現しなかった が，MRIにおいて，内頸動脈を再開させた際に生じた血 栓によると思われる小梗塞を右頭頂葉に認めた(Fig. 5).

\section{3. 長期予後}

術後，経過観察期間中， 4 例 $(5.5 \%)$ に脳虚血発作の再 発を認めた。その部位は， 3 例 (4.1\%)で手術側の内頸動 


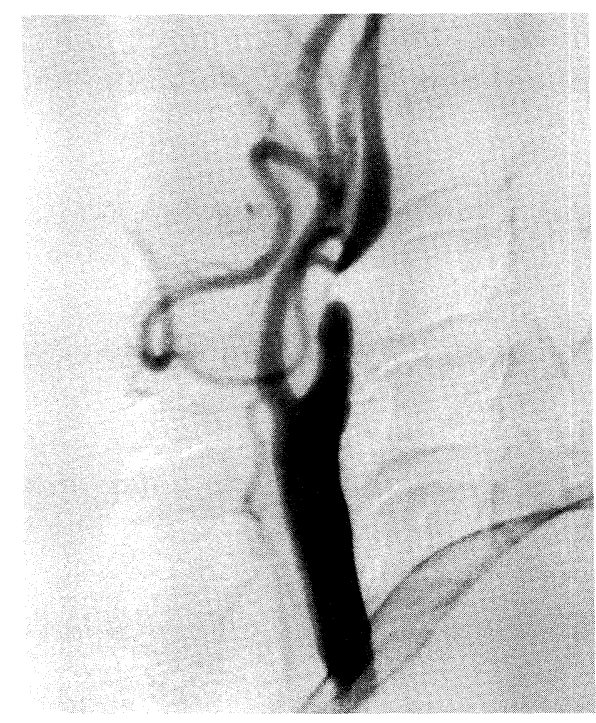

Fig. 3 Right carotid angiogram of 66-yearsold male (Case 3) who developed left hemiparesis, revealing marked stenosis of the right internal carotid artery.

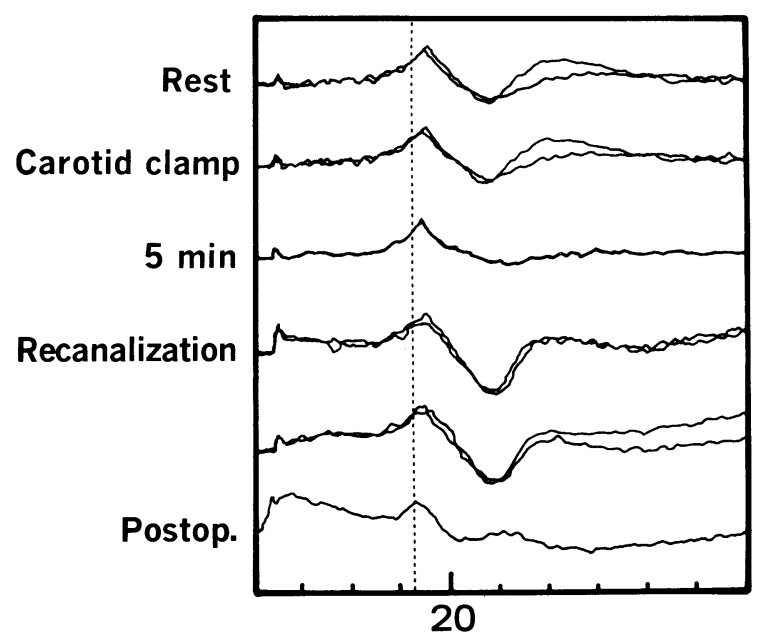

Fig. 4 Intraoperative somatosensory evoked potentials of Case 3, demonstrating decrease in $\mathrm{N}_{20}$ amplitude 5 minutes after carotid clamp for insertion of internal shunt.

脈領域，ほかの 1 例で椎骨脳底動脈領域であった. 手術か ら再発までの期間は 7 13 カ月 (平均 10.3 力月)であった (Table 2).また, 1 例が心筋梗塞により死亡した.

脳血管撮影では, 総頸動脈, 内頸動脈, 外頸動脈の閉塞 が, それぞれ 1 例ずつ認められた. しかし, 脳虚血発作を きたすには至らなかった。ささらに，再狭窄 (restenosis)を 1 例に認め, 再手術を施行した。

\section{考察}

CEA の有効性に関する検討は, 以前から多く行われて
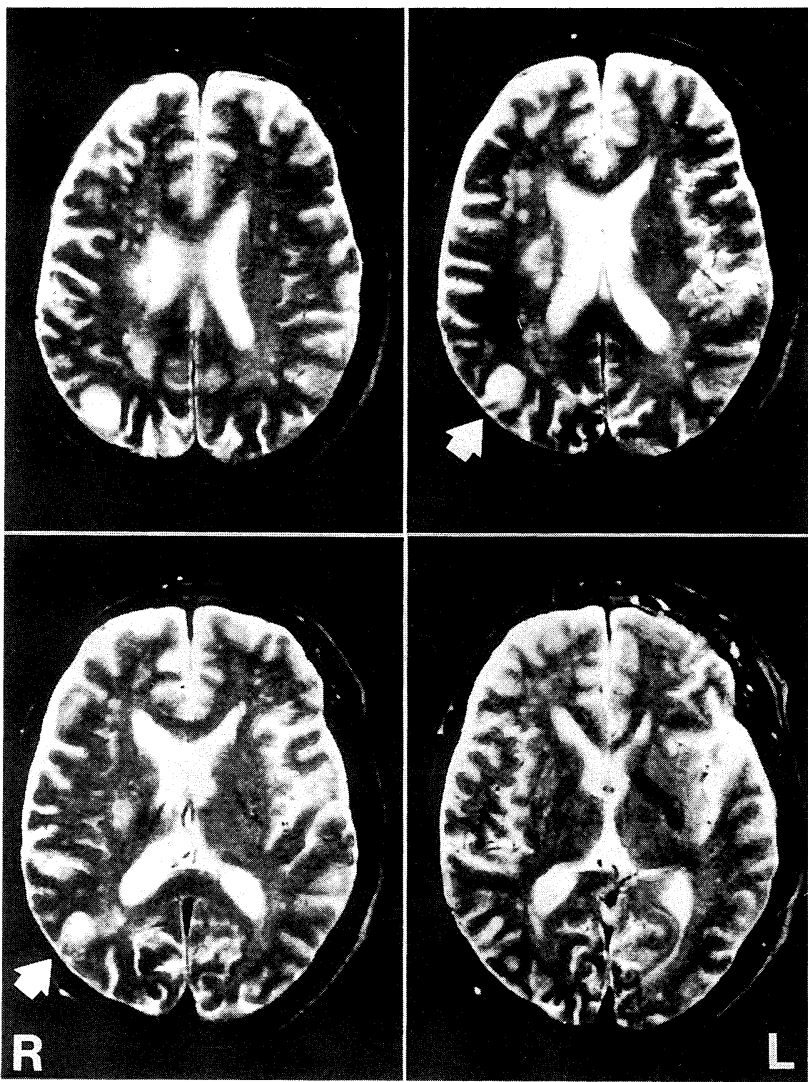

Fig. 5 Postoperative MRI ( $\mathrm{T}_{2}$-weighted images) of Case 3 , showing newly-developed high intensity area in the right parietal lobe, although no neurological deterioration was found after operation.

いるが2) 3) 5) 18) 20)，米国において行われたNASCET (North American Symptomatic Carotid Endarterectomy Trial) は，70\%以上の頸動脈狭窄を有する症候例では，外 科治療群が内科治療群に比べて, 明らかに脳梗塞の再発率 が低いと, 報告した ${ }^{12)}$ 。しかし, 中等度の狭窄例や無症 候例における結論は出ていず，今後の検討を待たねばなら ない4)11).

CEA が有効な術式として継続されるには，洗練された 手術適応の決定が必須と思われる. 手術適応の決定にあた っては，従来，脳血管撮影が最も重視されてきたが，提示 した症例のように，近年，多くの報告が脳血管撮影上， false-negative となる潰瘍がかなり存在すると指摘してい

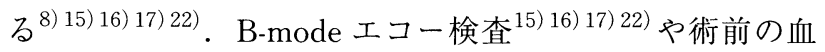
管内視鏡検査 ${ }^{77}$ ) などを用いて，より詳細に検討を重ねる 必要性を痛感した。

また，CEAを施行するにあたっては，術中および術後 に生じる合併症に十分な注意が必要である。

CEA 術中における合併症の頻度は 1 ～25\%とされてい

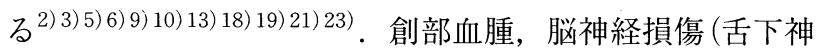


Table 2 Summary of 4 cases who developed ischemic stroke during follow-up periods

\begin{tabular}{|c|c|c|c|c|c|c|}
\hline & Age/Sex & Diagnosis & Postop. infarction & Sites & Duration & Angiography after recurrence \\
\hline Case 1 & $50 \mathrm{M}$ & $\begin{array}{l}\text { Lt. ICA stenosis } \\
(40 \% \text { \& ulcer })\end{array}$ & minor stroke & Lt. MCA territory & 13 months & not done \\
\hline Case 2 & $55 \mathrm{M}$ & Lt. ICA ulceration & minor stroke & pons & 9 months & no re-stenosis \\
\hline Case 3 & $65 \mathrm{M}$ & $\begin{array}{l}\text { Lt. ICA stenosis } \\
(75 \%)\end{array}$ & major stroke & Lt. centrum semiovale & 12 months & no re-stenosis, Lt. MCA occlusion \\
\hline Case 4 & $73 \mathrm{M}$ & Rt. ICA stenosis & major stroke & Rt. MCA territory & 7 months & not done \\
\hline
\end{tabular}

経, 迷走神経, 反回神経) などのほかに, 手術側内頸動脈 領域の脳梗塞や脳出血が術後の予後に大きな影響を及ぼす といわれている.

術後脳出血の原因は, 高度狭窄による hypoperfusion が 術後の normal perfusion breakthrough と類似した現象を 引き起こすためとされており, 術後の血圧管理が重要視さ れている ${ }^{114)}$. われわれも内頸動脈に高度の狭窄を有する 例に対しては, 術前, 脳血流量や脳血管反応性を検討し, hypoperfusion が著しい場合には術後の血圧管理を厳重に し，その発生の予防に努めているが，現在までに，この合 併症の経験はない。

脳梗塞の出現には, thromboembolic および hemodynamic mechanismによる 2 つメカニズムが考えられてい $b^{6)}$.

前者は, 術中は手術操作に, あるいは, 術後は動脈内腔 表面からの embolization によって生じ，いずれも重篤な 神経症状をきたすことが多いとされている ${ }^{6)}$ 。われわれが 術中に経験した 2 例においても，同様に重篤な神経症状を きたした。

また，これらを経験した当時(1985〜1988 年)は，2-way shunt tube を使用していたが，術中におけるチューブ内の patency 確認やチューブ内血栓の除去が困難であったこと も合併症の一因と思われた. 以後，3-way shunt tube を使 用するようになり，内膜剝離操作中にも頻回にチューブの patency の確認，チューブ内の washoutをするように努め た結果, その後, 脳塞栓による合併症は経験していない.

後者は, 内頸動脈の血流遮断に伴う脳血流量の著しい低 下が原因と考えられ，梗塞巣は watershed zone を中心に 出現するが，神経症状は， thromboembolic mechanismに よる場合に比べて軽度であるといわれている6)。われわれ の症例では，内シャントチューブを挿入するための短時間 の血流遮断中, SEP の $\mathrm{N}_{20}$ amplitude が急速に低下したり 遮断部より遠位の内頸動脈が血栓化するなど, stump pressure が著しく低值であったと考えられた. stump pressure が $40 \mathrm{mmHg}$ 以下になると, 脳虚血による合併症 の危険が高いとされている ${ }^{13)}$ ，今回，報告したわれわれ の症例では, stump pressure は測定していないが,このよ
うな例では, 内頸動脈の遮断前に stump pressure を測定 すること, heparinを投与すること, 少しでも短時間に挿 入できるようにシャントチューブの操作に習熟することが 必要と思われた。 また，このような例の場合には，特に脳 波やSEP といった術中モニタリングが特に重要であると 思われる.

また, perioperative strokeは, 反対側頸動脈に高度狭 窄病変を有したり，神経症状が不安定な症例に多く3）6）19）, mortality は, 冠動脈疾患, 重症高血圧や閉塞性呼吸器疾 患を有する症例に多いと報告されている ${ }^{19)}$ 。また，両側 頸動脈に対する同時手術や coronary artery byass との同 時手術も, strokeや mortalityの発生率を高めるとの報告 もある ${ }^{3)}$ 。手術適応の決定や術前，術中，術後の管理に際 しては, これらの点を十分, 考慮に入れるべきである.

\section{文献}

1) Andrew BT, Levy ML, Dillon W, et al: Unilateral normal perfusion breakthrough after carotid endarterectomy; Case report. Neurosurgery 21: 568-571, 1987

2) Committee on Health Care Issues, American Neurological Association: Does carotid endarterectomy decrease stroke and death in patients with transient ischemic attacks? Annals of Neurology 22: 72-76, 1987

3) Fode NC, Sundt TM Jr, Robertson JT, et al: Multicenter retrospective review of results and complications of carotid endarterectomy in 1981. Stroke 17: 370-376, 1986

4) Freischlag JA, Hanna D, Moore WS: Improved prognosis for asymptomatic carotid stenosis with prophylactic carotid endarterectomy. Stroke 23: 479-482 1982

5) Friedmann P, Grab JL, Berman, J, et al: Carotid endarterectomy-Clinical results in a community-based teaching hospital. Stroke 19: 1323-1327, 1988

6) Imparato AM, Ramirez A, Riles $\mathrm{T}$, et al: Cerebral protection in carotid surgery. Arch Surg 117: 1073-1078, 1982

7) Krul JMJ, van Gijin J, Ackerstaff RGA, et al: Site and pathogenesis of infarcts associated with carotid endarterectomy. Stroke 20: 324-328, 1989

8）黑田 敏, 米川泰弘, 河野輝昭, ほ力: 内澒動脈狭窄に対 する血管内視鏡の応用. 第 5 回日本脳神経血管内手術法研 究会講演集, 1991, pp 279-283

9) Kuroda S, Takahashi A, Saitoh $\mathrm{H}$, et al: Clinical application of angioscopy during carotid endarterectomy for patients with carotid artery stenosis. Neurol Med Chir (Tokyo) 1993 (in press) 
10) Lusby RJ, Wylie EJ: Complications of carotid endarterectomy. Surg Clin North Am 63: 1293-1302, 1983

11) Monata GL, Taylor DC, Nicholls SC, et al: Operative versus non-operative management of asymptomatic high-grade internal carotid artery stenosis; Improved results with endarterectomy. Stroke 18: 1005-1010, 1987

12) North American Symptomatic Carotid Endarterectomy Trial (NASCET) investigators: Clinical alert; Benefit of carotid endarterectomy for patients with high-grade stenosis of the internal carotid artery. Stroke 22: 816-817, 1991

13) Pedrini L, Paragona O, Pisano E, et al: Morbidity and mortality following carotid surgery. J Cardiovasc Surg 32: 720-725, 1991

14) Piepgras DG, Morgan MK, Sundt TM, et al: Intracranial hemorrhage after carotid endarterectomy. J Neurosurg 68: 532-536, 1988

15) Ricotta JJ, Schenk EA, Ekholm SE, et al: Angiographic and pathological correlates in carotid artery disease. Surgery 99: 284-292, 1986

16) Ricotta JJ, Bryan FA, Bond MG, et al: Multicenter validation study of real-time (B-mode) ultrasound, arteriography, and pathological examination. J Vasc Surg 6: 512-520, 1987

17) Senkowsky J, Bell WH, Kerstein MD: Normal angiograms and carotid pathology. The American Surgeon 56: 726-729, 1990

18) Spetzler RF, Martin N, Hadley MN, et al: Microsurgical en darterectomy under barbiturate protection; A prospective study. J Neurosurg 65: 63-73, 1986

19) Sundt TM Jr, Sndok BA, Whisnant JP: Carotid endarterectomy; Complications and preoperative assessment of risk. Mayo Clin Proc 50: 301-306, 1975

20) Tippett TM II, Sisco AB, Chapleau CE. et al: Carotid endarterectomy; Revew of 150 concecutive cases in two small community hospitals. J Neurosurg 63: 387-389, 1985

21) Toront Cerebrovascular Study Group: Risks of carotid endarterectomy. Stroke 17: 848-852, 1985

22) Wechsler LR: Ulceration and carotid artery disease. Stroke 22: $19-23,1987$

23）山田和雄, 伊藤 守, 種子田護, ほか：単一のチームによ る頸動脈内膜剝離術の手術成績. 脳卒中の外科 20: 276-281, 1992 